\title{
Endoscopic dacryocystorhinostomy to treat congenital nasolacrimal canal dysplasia: a retrospective analysis in 40 children
}

\author{
Yan-Hui Cui ${ }^{1,2}$, Cheng-Yue Zhang ${ }^{1}$, Wen Liu', Qian Wu', Gang Yu', Li Li ${ }^{1}$ and Wen-Bin Wei ${ }^{2 *}$
}

\begin{abstract}
Background: To investigate the therapeutic effectiveness and safety of endoscopic dacryocystorhinostomy (ENDCR) to treat congenital nasolacrimal canal dysplasia (CNCD).

Methods: Forty children (50 eyes) with congenital nasolacrimal duct obstruction (CNLDO) and lacrimal bony dysplasia, including 8 children with bony atresia (10 eyes) and 32 with bony stenosis (40 eyes), were recruited in this retrospective study. Standardized EN-DCR was performed in all cases. The postoperative observations included relief of symptoms, fluorescein dye disappearance test (FDDT), syringing of lacrimal passages and anastomotic patency under nasal endoscopy. Patients were followed up for 8-18 months.

Results: Standardized EN-DCR surgery had a success (cure and improvement) rate of 100\%, including a cure rate of $82 \%$ and an improvement rate of $18 \%$. The cure rate among 40 cases of bony nasolacrimal duct stenosis was $82.5 \%$, while that of 10 cases of bony nasolacrimal duct atresia was $80 \%$. Statistical analysis showed that nether the receipt of other treatments before surgery nor the type of bony nasolacrimal duct dysplasia affected the cure rate. No significant complications were observed during postoperative follow-up except for four cases (4 eyes) that suffered middle turbinate and nasal mucosal adhesion and two cases with sinusitis.

Conclusions: CNCD is a type of CNLDO that does not respond to conservative and conventional treatment. ENDCR represents a safe and effective treatment for children with CNCD. In addition, the combination of EN-DCR with lacrimal CT scanning provides advantages over traditional lacrimal surgery in that it has a high success rate with a low incidence of complications.
\end{abstract}

Keywords: Nasal endoscopy, Endoscopic dacryocystorhinostomy (EN-DCR), Children, Congenital nasolacrimal duct obstruction (CNLDO), Nasolacrimal canal dysplasia

\section{Background}

Congenital nasolacrimal canal dysplasia (CNCD) is a subtype of common congenital nasolacrimal duct obstruction (CNLDO) [1, 2]. This type of congenital lacrimal duct deformity results from a rudimentary or immature bony nasolacrimal duct. Several studies have used computed tomography (CT) scans to characterize the abnormal features of CNCD [1-5].

\footnotetext{
*Correspondence: weiwenbintr@163.com

${ }^{2}$ Beijing Tongren Eye Center, Beijing Tongren Hospital, Beijing key Laboratory of Intraocular Tumor Diagnosis and Treatment, Beijing Ophthalmology and Visual Science Key Lab, Capital Medical University, 1 Dong Jiao Min Xiang, Dong Cheng District, Beijing 100730, China

Full list of author information is available at the end of the article
}

Conservative and conventional therapy, such as spontaneous relief, massage, irrigation, lacrimal duct probing, and intubation surgery, are ineffective in CNCD. In recent years, nasal endoscopic surgical techniques have become more frequently used by ophthalmologists and ear-nose-throat physicians to treat lacrimal duct obstruction diseases and dacryocystitis. At present, endoscopic dacryocystorhinostomy (EN-DCR) is generally viewed as the only effective treatment for CNCD [6-8]. However, few reports have described the use of EN-DCR to treat $\mathrm{CNCD}$ in children [9-11]. In the present study, we report the clinical data of 40 pediatric cases (50 eyes) of CNCD treated with EN-DCR in our hospital from 2012 to 2016.

(c) The Author(s). 2019 Open Access This article is distributed under the terms of the Creative Commons Attribution 4.0 International License (http://creativecommons.org/licenses/by/4.0/), which permits unrestricted use, distribution, and 


\section{Methods}

\section{Patients}

Forty children (50 eyes) with CNCD who underwent EN-DCR in the Department of Ophthalmology, Beijing Children's Hospital, Capital Medical University, from February 2012 to March 2016 were recruited into this study.

The diagnosis of CNCD was based on the history provided by the parents, the presence of symptoms of postpartum tear discharge with eye discharge, tests of the patency of the nasolacrimal canal conducted by irrigating the lacrimal sac, and a plain CT scan examination of the lacrimal duct. All cases completed a lacrimal CT scan within one month before surgery. Based on the report by $\mathrm{Yu}$ et al. [1] and Zhang et al. [2], lacrimal bony dysplasia was divided into bone nasolacrimal duct stenosis and bone atresia using CT scans (Fig. 1).

The demographic and clinical information obtained in the patients is summarized in Table 1 . The inclusion criteria were CNLDO with lacrimal bony dysplasia and an age of 2-18 years. Exclusion criteria included anomalies of the initial segment of the lacrimal passage, such as an absent inferior lacrimal puncta, absence or atresia of the inferior canal, traumatic lacrimal duct obstruction, lacrimal fractures induced by trauma, or lacrimal sac damage or displacement [12].

The indications for EN-DCR included cases that had been clearly diagnosed as CNCD. This type of case was also suitable for external dacryocystorhinostomy (DCR). In all cases, the parents in this group chose EN-DCR.

\section{Ethics statement}

This study was a retrospective study conducted in accordance with the principles of the Helsinki Declaration and approved by the Institutional Review Committee of Beijing Children's Hospital. Written informed consent was obtained from the parents of all patients before surgical treatment.

\section{Surgical procedures}

All procedures were performed under general anesthesia. Patients were required to remain supine with the head tilted back $15^{\circ}$. The nasal cavity on the surgery side was shrunk by using 1:10000 adrenaline cotton pieces. An endoscopic surgical system (Karl Storz SE and Co. KG, Tuttlingen, German) and 4.0- $\mathrm{mm}, 0^{\circ}$ rigid nasal endoscopy (XiON GmbH, Berlin, German) were utilized. Other surgical equipment included an ENT power system (Medtronic PLC, Dublin, Ireland), a 4.0-mm ear burr, ophthalmic devices (including 3.0- and 2.0-mm rongeurs), and a Blasky child's mucosal biting clamp.

The EN-DCR procedure was divided into three steps according to the guidelines for rigid endoscopy [13] (Fig. 2). In step one, a $2.0 \times 1.5 \mathrm{~cm}$ mucoperiosteal flap was made in the lateral nasal wall using a sickle knife starting from the front of the uncinate process (located mainly above the middle turbinate axillary) and reaching the periosteum. In step two, a bone window was made. As shown in Fig. 1a-c, the frontal process of the maxilla was engaged using a rongeur from the suturae lacrimal maxillaris; the front lacrimal bone was separated and clamped, and a bone window was then formed with a diameter of about $1 \times 1.5 \mathrm{~cm}$. If the upper frontal process of the maxilla bone was thick, it could be ground down with an electric drill. Then, the medial lacrimal sac wall (with a light pale blue color) was exposed. After the lacrimal sac had been exposed, a Bowman probe was placed through the canaliculus into the sac. A vertical incision was then made with a sickle knife, and the medial wall of the sac was removed or the mucosal flap of the lacrimal sac was placed posteriorly, as shown in Fig. 1d-f. In step three, the lacrimal sac was filled with vampire gauze or a gelatin sponge, which was pressed against the lacrimal sac mucosal flap to reduce movement and promote epithelialization of the anastomosis and to attenuate early postoperative bleeding.

\section{Postoperative treatment and follow up}

Systemic antibiotics and hemostasis were administered for three days after surgery. Saline nasal sprays were recommended for use in the month after surgery. A nasal wash was performed beginning on the fourth day using a nose washing apparatus. The first postoperative follow-up was arranged for the seventh day after surgery, when patients were subjected to a lacrimal passage flush. A solution containing tobramycin and dexamethasone (diluted 1:10) was used to flush the lacrimal passage from the upper and the lower punctum. In general, the first flush met with significant resistance and was accompanied by pus discharge and regurgitation. Sustained pressure washing was recommended until flushing became smooth, swallowing was confirmed, and regurgitation disappeared or until the discharge reflux fluid became clear. In the first month after surgery, a lacrimal passage flush was performed weekly; then, it was performed every two weeks for another two months. After one month, anastomotic exploration was routinely performed in all cases under local anesthesia according to the patient's age, the degree of anastomotic epithelialization, and the timely discovery and cleaning of proliferated granulation tissue around the pore. At 8-18 months after the surgery, anastomotic exploration was again performed. Outpatient follow-up studies included a medical history, a fluorescein dye disappearance test (FDDT), lacrimal passage flush, and anastomotic exploration under nasal endoscopy in children $>6$ years old. The evaluation of duct drainage function by FDDT was considered a major endpoint (FDDT 0-1: none or a thin 

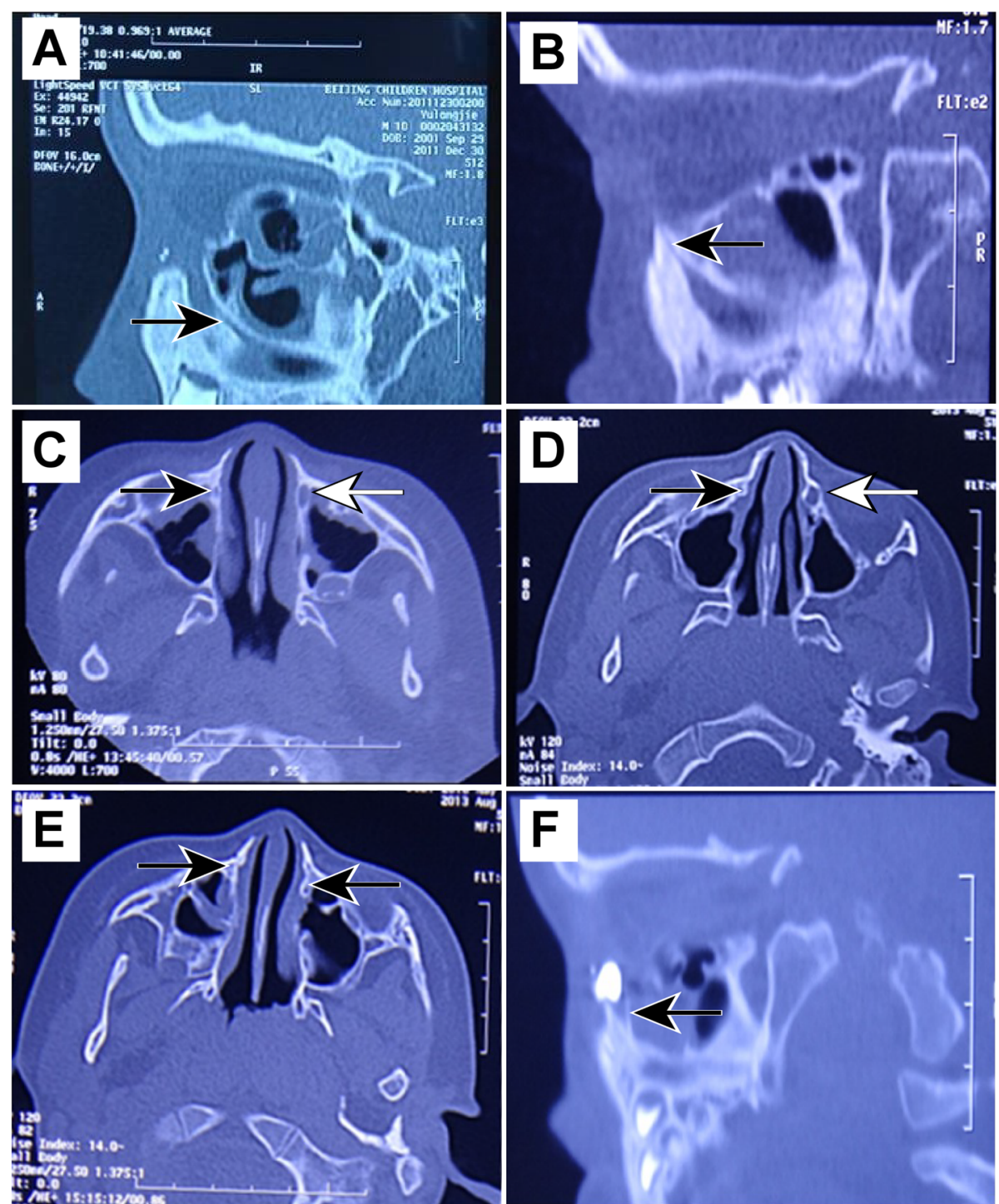

Fig. 1 Computed tomography angiography of the lacrimal duct allows congenital nasolacrimal canal dysplasia to be clearly distinguished. (a, b) The sagittal position of bony nasolacrimal duct stenosis (black arrow). (c, d) The horizontal position of bony nasolacrimal duct stenosis (black arrow) and the contralateral contrast (white arrow). (e, f) Both the horizontal and sagittal position show bilateral hypomere bony nasolacrimal duct atresia (black arrow)

fluorescing marginal tear strip that persists in the conjunctival sac and normal lacrimal drainage function; FDDT 2-3: fluorescein persists in the conjunctival sac and the lacrimal drainage system is obstructed) [13].

\section{Clinical criteria for surgery outcomes}

Surgical effects were divided into cure, improvement, and invalid, according to clinical criteria. Cure was defined as lacrimal sac pore formation in the lateral nasal wall in front of the middle concha, epithelialization under endoscopic observation, no tearing or pus, $\mathrm{FDDT}=0$, and smooth flush. Improvement was defined as lacrimal sac pore formation in the lateral nasal wall in front of the middle concha, epithelialization under endoscopic observation, symptom relief, $\mathrm{FDDT}=1$, and flush unobstructed or pressure flush unobstructed. Invalid was defined as no relief of symptoms, FDDT $=2-3$, flush unsmooth or pressurized, and pore atresia. Cure and improvement were considered successful surgery, and surgery efficiency was calculated as the sum of the cure rate and the improvement rate [14].

\section{Statistical analysis}

Statistical Package for the Social Sciences (SPSS) software (SPSS Inc. Released 2008. SPSS Statistics for Windows, Version 17.0. Chicago: SPSS Inc.) was used for statistical analysis. The efficacy of preoperative treatment and the effect of type of bony nasolacrimal duct dysplasia on the 
Table 1 The general clinical and demographic information of subjects

\begin{tabular}{|c|c|}
\hline Item & Data of all patients $(n=40)$ \\
\hline \multicolumn{2}{|l|}{ Gender } \\
\hline Male & $26 / 40(65 \%)$ \\
\hline Female & $14 / 40(35 \%)$ \\
\hline \multicolumn{2}{|l|}{ Age (years) } \\
\hline Average & 5.5 \\
\hline Median & 6 \\
\hline Range & $2-14$ \\
\hline \multicolumn{2}{|l|}{ Side (cases) } \\
\hline Bilateral & $12 / 40(30 \%)$ \\
\hline Right & $12 / 40(30 \%)$ \\
\hline Left & $16 / 40(40 \%)$ \\
\hline \multicolumn{2}{|l|}{ Preoperative treatment (eyes) } \\
\hline Probing & $16 / 50(32 \%)$ \\
\hline Intubation & $6 / 50(12 \%)$ \\
\hline Massaging & $28 / 50(56 \%)$ \\
\hline \multicolumn{2}{|l|}{ Type of bony dysplasia (eyes) } \\
\hline Stenosis & $40 / 50(80 \%)$ \\
\hline Atresia & $10 / 50(20 \%)$ \\
\hline \multicolumn{2}{|l|}{ Effects } \\
\hline Success rate & $50 / 50(100 \%)$ \\
\hline Cure rate & $41 / 50(82 \%)$ \\
\hline Improvement & $9 / 50(18 \%)$ \\
\hline \multicolumn{2}{|l|}{ Complications (cases) } \\
\hline Middle turbinate and nasal mucosal adhesion & 4 \\
\hline Nasosinusitis & 2 \\
\hline Other & 0 \\
\hline
\end{tabular}

cure rate were analyzed using the chi-square test, with $P<0.05$ representing statistical significance.

\section{Results}

Fifty endoscopic DCRs were performed on 40 patients (50 eyes) with CNCD. There were no intraoperative complications. The mean age at surgery was 5.5 years (range 2-14 years). The male to female ratio was 1.9:1 (26:14). Previous interventions included probing in $32 \%$ of patients (16/50), massage in 56\% (28/50) and intubation in $12 \%(6 / 50)$. The follow-up period was $8-18$ months (average 16.5 months). Preoperative plain CT scan of the lacrimal passage revealed 8 bony atresia cases in $20 \%(10 / 50)$ and 32 bony stenosis cases in $80 \%(40 /$ $50)$. The demographic information and clinical outcomes of cases are summarized in Table 1.

According to the criteria, the success rate was $100 \%(50 / 50)$, the cure rate was $82 \%(41 / 50)$ and the improvement rate was $18 \%(9 / 50)$. Patients in both the nasolacrimal canal stenosis and atresia groups achieved a high effective rate (Table 2). Chi-square analysis showed that the type of nasolacrimal duct dysplasia had no impact on the efficacy of surgical treatment based on the similar cure and improvement rates in both groups $\left(\chi^{2}=0.08, P=0.78\right)$. According to Table 3 , the chisquare test showed that the cure rate was not affected by treatments performed before EN-DCR $\left(X^{2}=1.17, P=0.28\right)$.

We explored the stoma one month after surgery in patients who received general or local anesthesia. Among the 40 patients, 6 cases ( 8 eyes) had no follow up on time, and the other 34 cases (42 eyes) were followed up on time. These had round or oval nasal anastomosis with healed mucosa with a maximum diameter of 6-7 mm (Fig. 3). However, visible mucosal thickening and edema remained, with bleeding upon tactile investigation. Among these 42 eyes, 32 had granulation in varying degrees. The early postoperative granulated tissue around the stoma was vulnerable and bled easier, making it accessible for removal using nasal mucosa pliers. After clearing the granulation tissue, bleeding was 

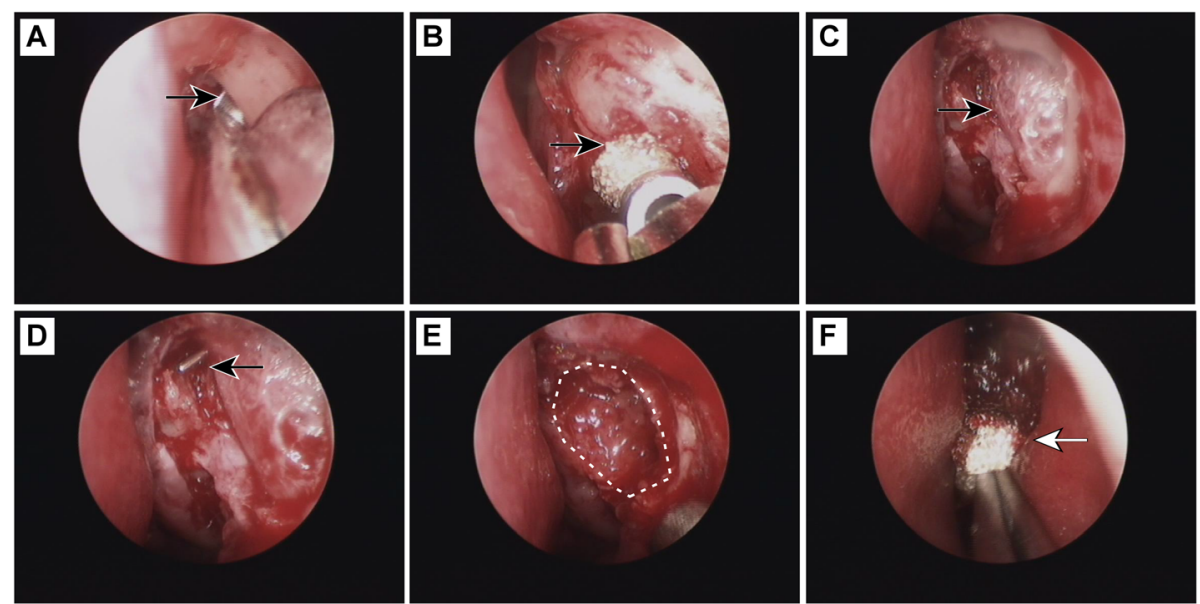

Fig. 2 Illustration of the steps of the operation. (a) Remove the frontal process of the maxilla and move the sutura lacrimal maxillaris forward with the rongeur (black arrow). (b) Use an electric drill to grind the thicker parts of the maxilla frontal process upper bone, if needed (black arrow). (c) After producing the bone window, expose the inner wall of the lacrimal sac (black arrow). (d) From the lacrimal point, insert the lacrimal probe into the lacrimal sac (black arrow) after endoscopy has verified accurate exposure of the lacrimal sac (black arrow). (e) A longitudinal incision is made along the lacrimal sac wall, and a crosscut incision is then made at the top and bottom of the initial incision to form a base at the edge of the lacrimal sac wall and form the mucosal flap. Flip the mucosal flap backward to expose the front mucous membrane of the uncinate process, leaving the lacrimal sac cavity completely open (white outline). (f) Blood should be absorbed by stuffing gauze into the lacrimal sac (white arrow), and the lacrimal sac mucosal flap should be pinned to reduce movement and bleeding

stopped with a gelatin sponge. Six cases (7 eyes) were followed up later than one month (2-3 months), by which time the mucosal edema was not obvious and the stoma had basically epithelialized. Four eyes had visible granulation tissue, which was surgically removed. Twenty-eight cases (36 eyes) who received anastomotic probing under general or local anesthesia were followed up after 8-18 months. The probing results showed that the anastomotic hole was round or oval and showed no atresia. The diameter of the anastomotic hole was approximately $2-5 \mathrm{~mm}$, and the maximum pore diameter was $5 \mathrm{~mm}$ (as shown in Fig. 3). The mucosa around the anastomosis was highly epithelialized and smooth without granulation tissue hyperplasia.

Few patients had significant complications during the operation or postoperative follow-up period. Adhesion of the middle turbinate to the lateral wall nasal mucosa was found in four cases (4 eyes) and separated through exploratory surgery. Four patients complained of occasional headache,

Table 2 The effect of type of bony nasolacrimal duct dysplasia on cure rate

\begin{tabular}{lllll}
\hline Type & Cure (\%) & Improvement (\%) & Invalid (\%) & Total \\
\hline St. & $33(82.5)$ & $7(17.5)$ & 0 & 40 \\
At. & $8(80)$ & $2(20)$ & 0 & 10 \\
Total & $41(82)$ & $9(18)$ & 0 & 50 \\
\hline
\end{tabular}

St. $=$ Stenosis of the nasolacrimal duct; At. $=$ Atresia of the nasolacrimal duct The chi-square test showed that the cure rate was not affected by type of bony nasolacrimal duct dysplasia $\left(x^{2}=0.08, P=0.78\right.$, no statistically significant difference) and two were diagnosed with nasosinusitis. Further observation was needed in these cases because no nasosinusitis was found in these four patients prior to surgery.

\section{Discussion}

CNCD is a particular type of CNLDO. The vast majority of cases of $\mathrm{CNCD}$ are initially diagnosed as common CNLDO and treated conservatively or conventionally, such as with massage, lacrimal duct probing, and intubation surgery. When these treatments prove ineffective, a CT scan examination of the lacrimal duct may reveal CNCD. A CT scan can precisely delineate the shape, direction, and abnormal structure of the bony nasolacrimal duct and provide a clear anatomical characterization of the abnormal nasolacrimal canal. These data can be used to categorize abnormalities of the nasolacrimal canal as significant stenosis or even atresia [2]. Prior to the use of lacrimal CT scans, many children suffered repeated lacrimal probing, which can cause complications such as false

Table 3 The effect of preoperative treatment on cure rate

\begin{tabular}{lllll}
\hline Group & Cure (\%) & Improvement (\%) & Invalid (\%) & Total \\
\hline $\mathrm{T}$ & $20(91)$ & $2(9)$ & 0 & 22 \\
$\mathrm{~N}$ & $21(75)$ & $7(25)$ & 0 & 28 \\
Total & 41 & 9 & 0 & 50
\end{tabular}

$\mathrm{T}=$ treated before surgery, such as receiving intubation and probing $N=$ not treated before surgery

The chi-square test showed that the cure rate was not affected by other treatments before endoscopic dacryocystorhinostomy $\left(X^{2}=1.17, P=0.28\right.$, no statistically significant difference) 

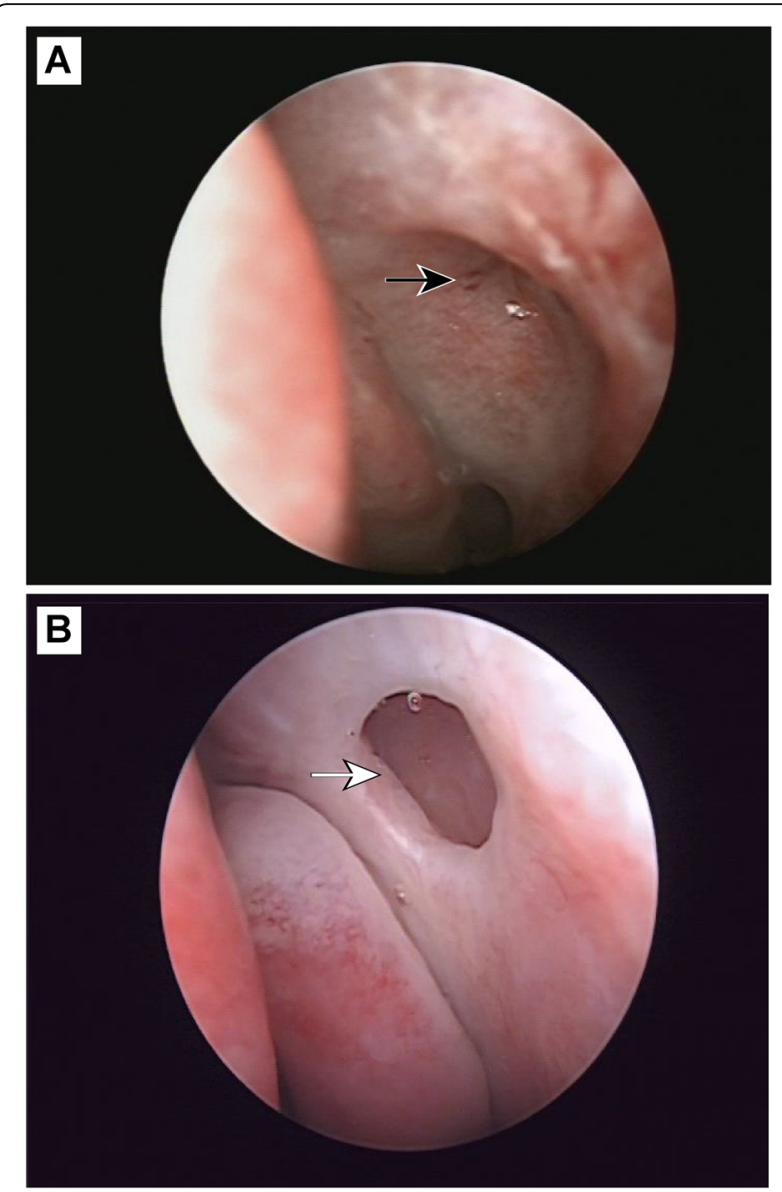

Fig. 3 Postoperative anastomotic opening. (a) The anastomotic opening is healing but still shows mild edema at 1 month postoperative (black arrow). (b) The anastomotic opening at 12 months postoperative, with epithelization (white arrow)

passages and punctal tears [12]. A CT scan can help diagnose congenital nasolacrimal duct abnormalities, thereby avoiding lacrimal tissue damage. Moreover, a CT scan of the lacrimal passage can not only accurately determine the location and degree of obstruction but also help to determine the developmental level of the agger nasi and its anatomic relationship with the lacrimal sac. In addition, it can help to identify abnormalities in the paranasal sinuses and lacrimal sac and can provide especially valuable information in patients with surgical histories. We previously performed CT scans in children with failed lacrimal probing and found that these children had bony nasolacrimal canal stenosis or atresia $[1,2]$. We recommend that these children should stop receiving lacrimal probing and should undergo EN-DCR.

EN-DCR is now a widely-accepted technique for managing nasolacrimal duct obstructions with success rates comparable to those of external DCR [15-19]. EN-DCR represents a mature technology used to treat complex nasal lacrimal duct obstructions in children [12].
Previous studies have achieved success rates in pediatric EN-DCR of 58-100\% [20]. Leibovitch et al. [21] reported that while the anatomical patency rate was 100\% (endoscopic anastomotic opening), the success rate (complete disappearance of symptoms) was only $92 \%$. In our study of the application of EN-DCR in the treatment of CNCD, the success rate was $100 \%(50 / 50)$, the cure rate was $82 \%(41 / 50)$, and the improvement rate was $18 \%(9 / 50)$, similar to the results obtained in previous studies. In particular, combining EN-DCR with lacrimal CT scan provides advantages over traditional lacrimal surgery. In addition, few patients experienced significant complications during either the operation or the postoperative follow-up period. Adhesion of the middle turbinate to the lateral wall nasal mucosa was found in four cases (4 eyes) and was separated through exploratory surgery. In our experience, EN-DCR is not recommended in children younger than two years. In cases in which bone dysplasia is observed on CT scan, age is not a key consideration for EN-DCR. These children also have serious dacryocystitis symptoms, and their intubation success rate is very low. Additionally, repeated intubation or probing can easily cause false passage and infection. If ENDCR must be performed in very young children, the skill of the surgeons and the equipment used must be optimal.

For children with lacrimal duct obstruction, the initial EN-DCR can not only avoid skin scarring but also protect the exhaust pump function of the orbicularis muscle and the medial canthal ligament. Because it involves the use of sophisticated endoscopic equipment and intranasal devices, EN-DCR may obtain a clearer operating field, cause fewer injuries, and result in less bleeding and shorter operation times than are achieved using external DCR. These advantages are important for children who need general anesthesia. Postoperatively, external operations require nasal packing, daily flush washing early in the postoperative stages, wound care, and stitches, and they therefore have a higher chance of infection. While transnasal surgery requires simpler postoperative treatment, it is also necessary to perform intranasal anastomotic exploration in young children during the early postoperative stage (within one month), and this is usually performed under general anesthesia. We explored the stoma using sevoflurane under general anesthesia and treated tissues that exhibited granulation in young children.

Because of the small anatomical space in young children, a $2.7-\mathrm{mm}$ endoscope [22] as well as a nasal trumpet are recommended. However, some scholars have held that a 4.0-mm endoscope can be used in children younger than one year because it can provide better lighting and a wider viewing angle; however, the results depend on the endoscopic surgeon's skill level, personal preferences, and device conditions [6]. In this study, the youngest child was 2 years old, and a 4.0-mm endoscope was successfully used in this patient, providing better 
lighting and a wider visual field than was achievable with a $2.7-\mathrm{mm}$ endoscope. The medial wall of the lacrimal sac may become thick due to inflammation, and we therefore recommend using a corneal puncture with a $15^{\circ}$ blade; however, some surgeons may be more accustomed to using a sharp sickle knife, a myringotome, a high-frequency electric knife, or a laser [22]. Experts agree that achieving successful outcomes in pediatric DCRs requires adequately sized and positioned osteotomy, full-length sac marsupialization, and a $360^{\circ}$ mucosa-tomucosa approximation to facilitate healing [23].

A large bone window is recommended when exposing the inner lacrimal wall as this will improve the opening rate of the pore [21]. However, a small bone window will be susceptible to blockage by a postoperative blood scab, exudate, or granulation tissue, resulting in a failed operation.

The use of lacrimal stents in pediatric cases is controversial [24-26]. Some studies have recommended that a lacrimal silicone tube should be placed in all EN-DCR patients for four weeks to expand the tear duct and sac opening instead of allowing the lacrimal sac to remain open [23]. We conclude that in cases with bony nasolacrimal duct stenosis or atresia, the lacrimal sac and the surrounding bones should be allowed to develop normally or even expand slightly so that the lacrimal bone hole fits easily with the nasal mucosal flap and nasal mucosa. If there is no canalicular lesion, it is not necessary to place any anastomotic support. This approach also avoids a second surgery to remove the tube. Ensuring a good nasal mucosal flap and lacrimal sac is important for the success of the operation. Vampire gauze or gelatin sponge can also be used as a short-term support for the anastomosis of the lacrimal sac and to press the nasal mucosa and lacrimal mucosa together to stop bleeding. By the time the vampire gauze or gelatin sponge is absorbed, anastomotic mucosal healing should be largely complete. Therefore, the decision to place a lacrimal duct support depends on the child's condition. An important prerequisite to ensuring the success of this surgery is a superb endoscopic sinus surgery technique and a deep familiarity with the sinonasal anatomy and the structural relationships around the eyes. In this study, none of the cases underwent lacrimal duct dilatation or catheter tube placement.

\section{Limitations}

The limitations of the current study include its retrospective and single-center design. The limited sample size prevented group comparisons.

\section{Conclusions}

In summary, CNCD is a type of CNLDO that does not respond to conservative and conventional treatment. EN-DCR is a safe and effective treatment for children with CNCD. In addition, the combination of EN-DCR with lacrimal CT scan provides advantages over traditional lacrimal surgery: it has a high success rate and a low incidence of complications. Multicenter studies should be performed to confirm these conclusions.

\section{Abbreviations}

CNCD: Congenital nasolacrimal canal dysplasia; CNLDO: Congenital nasolacrimal duct obstruction; CT: Computed tomography;

DCR: Dacryocystorhinostomy; EN-DCR: Endoscopic dacryocystorhinostomy; FDDT: Fluorescein dye disappearance test; SPSS: Statistical Package for the Social Sciences

\section{Acknowledgements}

Not applicable.

\section{Availability of data and material}

The datasets used and/or analyzed during the current study are available from the corresponding author on reasonable request.

\section{Authors' contributions}

YHC carried out the endoscopic DCR surgeries and drafted this manuscript. $\mathrm{CYZ}$ participated in the design of the study and performed the data analysis. WL collected important background information. QW drafted and revised the manuscript. GY and LL participated in experimental design and coordination and helped to draft the manuscript. WBW designed this study and guided the surgery and data collection. All authors read and approved the final manuscript for submission.

\section{Funding}

This research was supported by the National Natural Science Foundation of China (No. 81570891); Beijing Natural Science Foundation (No. 7151003); Supported by the Beijing Municipal Administration of Hospitals' Ascent Plan (DFL20150201); Advanced Health Care Professionals Development Project of Beijing Municipal Health Bureau (No. 2014-2-003); The Capital Health Research and Development of Special (No. 2016-1-2051); Beijing Municipal Administration of Hospitals Clinical Medicine Development of Special Funding Support (No. ZYLX201307); Science \& Technology Project of Beijing Municipal Science \& Technology Commission (No. Z181100001818003, Z151100001615052), including collecting data and writing the manuscript.

Ethics approval and consent to participate

This retrospective case series was approved by the ethics committee at Beijing Children's Hospital and conducted in accordance with the principles of the Helsinki Declaration. Written informed consent was obtained from the parents of all patients before surgical treatment.

\section{Consent for publication}

All of the authors agreed to publish the article. We believe all identifying information has been appropriately anonymised and there are no identifying images used within the manuscript.

\section{Competing interests}

The authors declare that they have no conflict of interest.

\section{Author details}

${ }^{1}$ Department of Ophthalmology, Beijing Children's Hospital, National Center for Children's Health, National Key Discipline of Pediatrics, Capital Medical University, Ministry of Education, Beijing 100045, China. ${ }^{2}$ Beijing Tongren Eye Center, Beijing Tongren Hospital, Beijing key Laboratory of Intraocular Tumor Diagnosis and Treatment, Beijing Ophthalmology and Visual Science Key Lab, Capital Medical University, 1 Dong Jiao Min Xiang, Dong Cheng District, Beijing 100730, China.

Received: 19 May 2019 Accepted: 22 November 2019

Published online: 03 December 2019

References

1. Yu G, Zhang CY, Cui YH, Fan YW, Cao WH, Lin Q, et al. Application value of computed tomography dacryocystography in children lacrimal diseases. Zhonghua Yan Ke Za Zhi. 2013;49:706-10. 
2. Zhang C, Yu G, Cui Y, Wu Q, Wei W. Anatomical characterization of the nasolacrimal canal based on computed tomography in children with complex congenital nasolacrimal duct obstruction. J Pediatr Ophthalmol Strabismus. 2017;54:238-43.

3. Moscato EE, Kelly JP, Weiss A. Developmental anatomy of the nasolacrimal duct: implications for congenital obstruction. Ophthalmol. 2010;117:2430-4.

4. Weiss AH, Baran F, Kelly J. Congenital nasolacrimal duct obstruction: delineation of anatomic abnormalities with 3-dimensional reconstruction. Arch Ophthalmol. 2012;130:842-8.

5. Limongi RM, Magacho L, Matayoshi S, Carneiro HM, Avila M. Computed tomographic dacryocystography in children undergoing balloon dacryoplasty. J AAPOS. 2012;16:464-7.

6. Rice DH. Endoscopic intranasal dacryocystorhinostomy results in four patients. Arch Otolaryngol Head Neck Surg. 1990;116:1061.

7. Chan W, Wilcsek G, Ghabrial R, Goldberg RA, Dolman P, Selva D, et al. Pediatric endonasal dacryocystorhinostomy: a multicenter series of 116 cases. Orbit. 2017;36:311-6.

8. McDonogh M, Meiring JH. Endoscopic transnasal dacryocystorhinostomy. J Laryngol Otol. 1989;103:585-7.

9. Cunningham MJ, Woog JJ. Endonasal endoscopic dacryocystorhinostomy in children. Arch Otolaryngol Head Neck Surg. 1998;124:328-33.

10. Woog JJ, Kennedy RH, Custer PL, Kaltreider SA, Meyer DR, Camara JG. Endonasal dacryocystorhinostomy: a report by the American academy of ophthalmology. Ophthalmol. 2001;108:2369-77.

11. Cunningham MJ. Endoscopic management of pediatric nasolacrimal anomalies. Otolaryngol Clin N Am. 2006;39:1059-74.

12. Cao WH, Wu Q, Fan YW, Zhang CY, Yu G. Lacrimal intubation with the ritleng system for refractary nasolacrimal duct obstruction in children. Ophthalmol China. 2011;20:302-6.

13. Kominek P, Cervenka S, Matousek P, Pniak T, Zelenik K. Primary pediatric endonasal dacryocystorhinostomy--a review of 58 procedures. Int J Pediatr Otorhinolaryngol. 2010;74:661-4.

14. Metson R. Endoscopic surgery for lacrimal obstruction. Otolaryngol Head Neck Surg. 1991;104:473-9.

15. Huang J, Malek J, Chin D, Snidvongs K, Wilcsek G, Tumuluri K, et al. Systematic review and meta-analysis on outcomes for endoscopic versus external dacryocystorhinostomy. Orbit. 2014;33:81-90.

16. Karim R, Ghabrial R, Lynch T, Tang B. A comparison of external and endoscopic endonasal dacryocystorhinostomy for acquired nasolacrimal duct obstruction. Clin Ophthalmol. 2011;5:979-89.

17. Ali MJ, Psaltis AJ, Murphy J, Wormald PJ. Powered endoscopic dacryocystorhinostomy: a decade of experience. Ophthalmic Plast Reconstr Surg. 2015;31:219-21.

18. Tsirbas A, Wormald PJ. Endonasal dacryocystorhinostomy with mucosal flaps. Am J Ophthalmol. 2003;135:76-83.

19. Tsirbas A, Wormald PJ. Mechanical endonasal dacryocystorhinostomy with mucosal flaps. Br J Ophthalmol. 2003;87:43-7.

20. Ali MJ, Paulsen F. Syndromic and nonsyndromic systemic associations of congenital lacrimal drainage anomalies: a major review. Ophthalmic Plast Reconstr Surg. 2017;33:399-407.

21. Leibovitch I, Selva D, Tsirbas A, Greenrod E, Pater J, Wormald PJ. Paediatric endoscopic endonasal dacryocystorhinostomy in congenital nasolacrimal duct obstruction. Graefes Arch Clin Exp Ophthalmol. 2006;244:1250-4.

22. Kominek P, Cervenka S. Pediatric endonasal dacryocystorhinostomy: a report of 34 cases. Laryngoscope. 2005;115:1800-3.

23. Ali MJ, Psaltis AJ, Bassiouni A, Wormald PJ. Long-term outcomes in primary powered endoscopic dacryocystorhinostomy. Br J Ophthalmol. 2014;98:1678-80.

24. Bothra N, Naik MN, Ali MJ. Outcomes in pediatric powered endoscopic dacryocystorhinostomy: a single-center experience. Orbit. 2019;38:107-11.

25. Ali MJ. Pediatric dacryocystorhinostomy. Indian J Ophthalmol. 2017;65:1008-9.

26. Madge SN, Selva D. Intubation in routine dacryocystorhinostomy: why we do what we do. Clin Exp Ophthalmol. 2009;37:620-3.

\section{Publisher's Note}

Springer Nature remains neutral with regard to jurisdictional claims in published maps and institutional affiliations.

Ready to submit your research? Choose BMC and benefit from:

- fast, convenient online submission

- thorough peer review by experienced researchers in your field

- rapid publication on acceptance

- support for research data, including large and complex data types

- gold Open Access which fosters wider collaboration and increased citations

- maximum visibility for your research: over $100 \mathrm{M}$ website views per year

At BMC, research is always in progress.

Learn more biomedcentral.com/submissions 